\title{
Award-winning papers in 2012
}

Papers published in Engineering and Computational Mechanics are eligible for awards from the Institution of Civil Engineers. Papers from any of the ICE journals can be nominated for several awards. In addition, each journal has awards dedicated to their specific subject area.

On Friday 18 October 2013, ICE president Barry Clarke presented awards to the following papers published in Engineering and Computational Mechanics in 2012. The editorial panel nominated their best papers and an awards committee chaired by David Balmforth allocated the awards.

\section{Telford Premium Prize}

The Telford Premium Prize was awarded to Klettner et al. (2012).

\section{Abstract}

The dynamics of waves and their interaction with a beach depends on whether the leading wave component is elevated or depressed. These differences are explained in this paper using a hydraulic model and the principle of conservation of impulse. Laboratory experiments of depression waves, conducted using a novel wavemaker, are compared with model predictions. Over a sloping beach, these waves have a nearly constant V-shaped depression trailed by a growing $\Lambda$-shaped positive wave. The shoreline recedes over a significant distance, caused by shoreward water being drawn into the $V$-shaped depression. When the trailing $\Lambda$-shaped positive wave breaks, an energetic hydraulic bore develops and moves up the beach. The hydraulic model leads to general formulae for wave slopes, draw-down and run-up. The run-up of negative waves can be larger or smaller than that of positive waves, depending on the wave amplitude and beach parameters. The predictions are compared with results from photographs of depression waves taken during the 2004 Sumatra tsunami. Similar phenomena occurred in Japan in 2011. By incorporating up/down amplitude data in new tsunami warning systems, the properties of tsunamis on beaches could be estimated in real time using the present work, thus improving emergency response strategies. In future, the damage associated with tsunami waves, depending on coastal parameters, could increase with rising sea levels, erosion and destruction of coral reefs, and the loss of Arctic sea-ice.

\section{David Hislop Prize}

The David Hislop Prize, awarded for the best paper on heavy marine design and construction with particular reference to offshore engineering, was awarded to Sobey (2012).

\section{Abstract}

Analytical solutions for steady progressive waves in deep and shallow water are developed and explored. The solution presentations emphasise the significant overlap in their formulations. Each theory is numerically confirmed as correct to fifth order and details of the solutions are archived in a manner that anticipates application code. Finally, the limits of validity, separate and overlapping, of the respective analytical solutions are extensively examined. It is suggested that $\omega^{2} h / g \approx 0.65$ separates the region of applicability of the shallow and deep water theories.

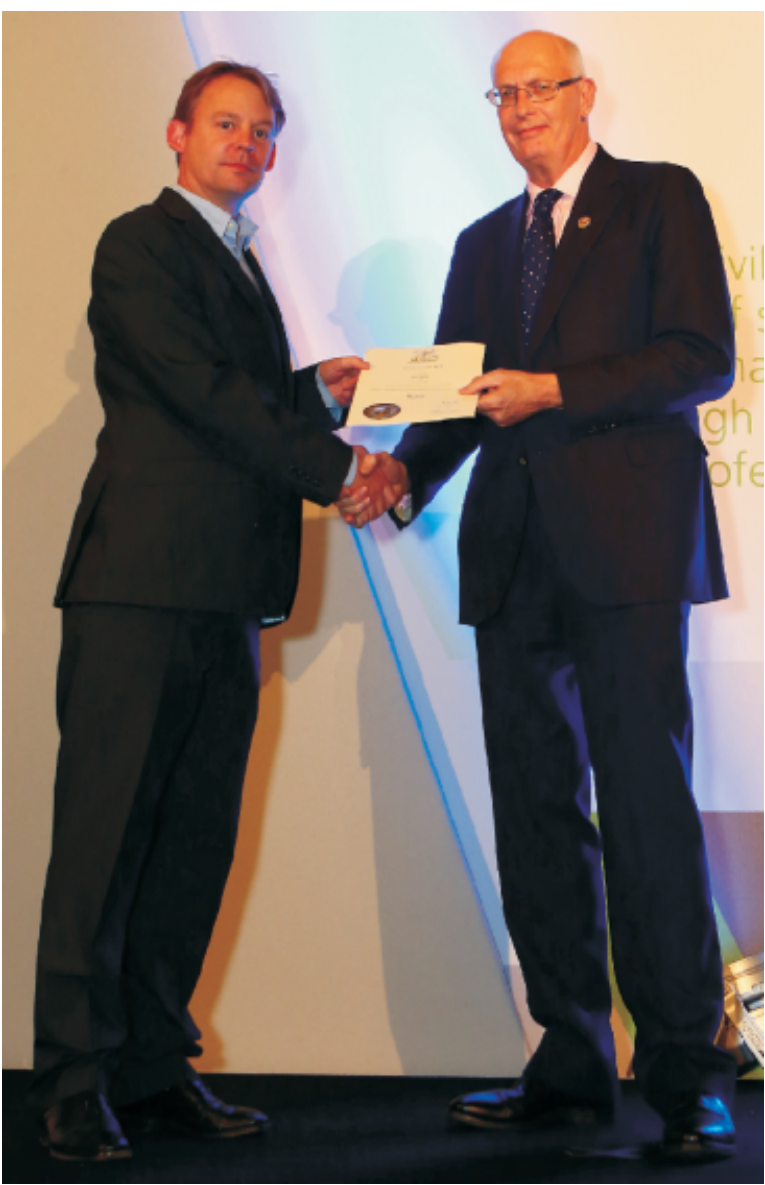

Ian Eames receiving the Telford Premium Prize from ICE President Barry Clarke

\section{REFERENCES}

Klettner C, Balasubramanian S, Hunt J, Fernando H, Voropayev S and Eames I (2012) Draw-down and run-up of tsunami waves on sloping beaches. Proceedings of the Institution of Civil Engineers - Engineering and Computational Mechanics 165(2): 119-129, http://dx.doi.org/10.1680/eacm.10.00044. Sobey RJ (2012) FE homogenised limit analysis model for masonry structures. Proceedings of the Institution of Civil Engineers - Engineering and Computational Mechanics 165(3): 181-200, http://dx.doi.org/10.1680/eacm.10.00013. 